\title{
Quorum Sensing: Survival Strategy of Microbes
}

\author{
Vandita kohli $^{*}$, Saima Rehman ${ }^{2}$, Srinu Rathlavath $^{3}$ and Deepak Aggarwal $^{4}$ \\ ${ }^{1}$ Quality Control Laboratory, Department of Post-Harvest Technology, ICAR-Central \\ Institute of Fisheries Education (CIFE), Mumbai-400061, India \\ ${ }^{2}$ Marine Biotechnology DivisionMadras Research Centre of Central Marine Fisheries \\ Research Institute, Chennai, Tamil Nadu-600028, India \\ ${ }^{3}$ College of Fisheries Science, Pebbair, Wanaparthy, Telangana-509104, India \\ ${ }^{4}$ College of Fisheries Science, Birsa Agriculture University, Ranchi, Jharkhand-834006, India \\ *Corresponding author
}

\section{A B S T R A C T}

Keywords

Quorum sensing, Survival strategy, Microbes

Article Info

Accepted:

04 April 2018

Available Online:

10 May 2018
Sounds strange that bacteria can talk to each other, though not verbally like humans but with the help of chemical signals which bacteria produce by forming biofilm, producing virulence factors or developing antibiotic resistance. The process starts only when the bacterial cell reach a threshold density enough to produce signals which can be detected by the receptors. This unique communication system is very specific to every bacteria and therefore a clear understanding of the quorum sensing mechanism of bacteria helps in developing various techniques for combating the attack of deadly pathogens, production of antibiotics and also using quorum sensing in different sectors of microbiology.

\section{Introduction}

Bacteria can sense an increase in the cell population density by the production and excretion of low-molecular-weight signaling molecules (autoinducers, AI). When bacterial population reaches the critical level of density, AIs bind to specific receptor regulatory proteins, which induce the expression of target genes. By means of Als, bacteria transmit information between bacteria belonging to the same or different species, genera, and even families (Asad and Opal, 2008). This type of mechanism is called Quorum Sensing (Diggle and Williams, 2017;
Waters and Bassler, 2005). Bacteria of different taxonomic groups use the Quorum sensing (QS) systems in regulation of a broad range of physiological activities. These processes include virulence, symbiosis, conjugation, biofilm formation, bioluminescence, synthesis of enzymes, antibiotic substances (Papenfort and Bassler, 2016). Here we review different Quorum sensing systems of bacteria and the role of QS in bacterial communication. This unique communication system is very specific to every bacteria. A clear understanding of the quorum sensing mechanism will help in designing activities to inactivate the signals of 
disease-causing pathogens, food spoilers, fermenters and biofilm formers(Hughes and Sperandio, 2008).

\section{Communication among Gram negative bacteria}

Among the Gram-negative spectrum of bacteria, a variety of acyl homoserine lactones (AHL's) is produced for inter-species, intraspecies, and inter-kingdom communication (de Kievit and Iglewski, 2000).

\section{Vibrio fischeri}

The idea about bacterial communication came into existence nearly 40 years ago with Vibrio fischeri. Bioluminescence in Euprymnascolopes (Hawain squid) is due to quorum sensing mechanism of the Vibrio fischeri (Nealson et al., 1970) which is living in symbiotic association with squid. When the bacteria multiply and reach at a particular threshold density chemical signals in the form of proteins are produced i.e., LuxI and LuxR controlling the expression of luciferase operon (light production) (Waters and Bassler, 2005). Among the two proteins, LuxI produces $\mathrm{N}$-(3-oxododecanoyl)-L-homoserine lactone (3OC6-HSL) and LuxR is a transcriptional precursor which is activated by this auto inducer to increase transcription of the luciferase operon. When the produced signals reach maximum level they form LuxR-AHL complex activating the luciferase enzyme encoded by luciferase operon (Stevens et al., 1994) and thus causing the light organs to illuminate.

\section{E. coli}

Quorum sensing in Escherichia coli has been observed for invading the host environment employing chemical signals like indole, which results in increasing the antibiotic resistance or expression of virulence among its bacterial population (Vega et al., 2013). Homologues of LuxR (Wang et al., 1991) and noradrenaline (NA) (Hughes and Sperandio, 2008) results in abnormal division in cell causing bloody diarrhoea due to enterohaemorrhagic E. coli (EHEC), (Knutton et al., 1987; Moon et al., 1983). EPEC contains a Shiga-like toxin which leads to apoptosis of the endothelial cells causing bloody diarrhea (Karmali et al., 1983; Tu et al., 2003). Around the world these chemical signals activate the virulence gene required for invasion of the host cell (Sperandio et al., 2003; Tannock et al., 2005).

\section{Salmonella}

This facultative anaerobic bacterium (Daoust, 1997; Ibarra and Steele-Mortimer, 2009) uses the mechanism of bacterial communication for antibiotic resistance, expression of virulent genes for host cell invasion. In the case of Salmonella, several auto inducing molecules like SdiA control some genes directed for resistance (Ahmer et al., 1998; Walters and Sperandio, 2006). Indole also acts as a signaling molecule, but the interesting part is though Salmonella does not produce indole but in mixed cultures, if indole is present it tends to increase the tolerance against a wide spectrum of antibiotics making the disease control tactics difficult (Vega et al., 2013). LuxS (signaling molecule) act as a precursor for the transcription of a number of virulent genes. It activates the Type III secretion system required by the bacteria for injecting the virulent genes (Mota and Cornelis, 2005) in the host's defense system for colonization the host cell (Wang et al., 2001)

\section{Burkholderia thailandensis}

This Gram-negative, non-fermenting, motile bacillus is a natural inhabitant of soil and aetiological agent of melioidosis, well known 
to form bio-film helping the bacteria to subsist in the host and natural environment. Bio-film formation is mediated by AHL quorum sensing mechanism for signal production (LuxI) and signal receptor (LuxR59) also acting as transcriptional factor. The signals so produced are a combination of three acyl- homoserine lactones (QS-1, QS-2 and QS-3). Of which QS-1, a pair of BtaI1BtaR1 which aids in development of biofilm. QS-2 is a pair of BtaI2-BtaR2 and $\mathrm{N}$-3hydroxy-decanoyl homoserine lactone (3OHC10-HSL) and QS-3 consists of BtaI3BtaR3 and $N$-3-hydroxy-octanoyl homoserine lactone (3OHC8-HSL) (Tseng et al., 2016).

\section{Pseudomonas aeroginosa}

This gram-negative, citrate, oxidase and catalase (Walker et al., 2004) positive group of bacteria resides in soil, water (Wong et al., 2012) having around 100 genes controlled by quorum sensing encoding the virulence (Singh et al., 2000; Yoon et al., 2002). $P$. aeroginosa enters into the lungs, forms biofilm, secretes deadly virulent factors like proteases, hydrolases damaging the lung tissue and thus causing respiratory infection (Smith and Iglewski, 2003). In this bacteria, the whole process of invasion to the host lungs is by using auto inducers LasIR and Rh1IR which activates the target genes of the bacterium for causing infection (Gambello and Iglewski, 1991; Lu et al., 2018; Ochsner et al., 1994).

This bacterium also expresses the cas gene of CRISPR using QS system which can shootup CRISPR-Cas target of foreign DNA and promote CRISPR's adaptation at high cell density ensuring its function under the threat of phage infection. CRISPR-Cas are popular gene editing tools for knocking out / knocking down any gene of interest causing mutation. Therefore, inhibition of quorum sensing can help in restraining CRISPR-Cas adaptive system of immunity for medical relevance (Hogan, 2006).

\section{Communication among gram positive bacteria}

Unlike, gram negatives, gram-positive bacteria induce the production of oligopeptides (auto inducing peptides, AIP's) instead of acyl homoserine lactones for communication. These bacteria are known for their high resistant nature by developing spores to survive at times of unfavorable conditions, the strategy for survival is coordinated by bacteria through bacterial communication. A slight difference lies in the mechanism of expression in gram-positive as these peptides cannot penetrate the cell wall on their own and therefore, need an oligopeptide exporter to translocate these signals to the cell wall. One of the best examples of gram-positive bacteria employing the concept of quorum sensing for infection is Staphylococcus aureus, other bacteria like Bacillus, Streptococcus etc also use quorum sensing for their survival (Paharik et al., 2017).

\section{Staphylococcus aureus}

Staphylococcus aureus being catalase positive nitrate reducing bacterial pathogen is known to produce lethal staphylococcal toxin and is a very potent pathogenic bacteria causing infection in both humans and animals. This facultative anaerobe, when present in few numbers only express the factors responsible for adhesion and colonization in the host cell whereas when they multiply in numbers and reach a threshold cell density, they start producing the lethal toxin causing meningitis and sepsis in the human body(Lyon and Novick, 2004). Quorum sensing system has been assigned a central role in the pathogenesis of staphylococci, particularly Staphylococcus aureus via the accessory gene 
regulator (agr). Here agr quorum sensing system (agr A, B, C, D) facilitates gene expression. In agr quorum sensing system, agr D encodes the Staphylococcus aureus auto inducing peptides (AIP)with respect to the cell density (Ji et al., 1995). The agrB protein helps the Staphylococcus aureus AIP's to bind to the thio-lactone ring (Saenz et al., 2000). The moment AIP (chemical signal) bind to the agrC protein, phosphorylation in the agrA commences expressing rRNA III promoting the expression of secreted factors and inhibiting the cell adhesion factors (Novick et al., 1993), activation of agr A protein triggers the agr BDCA gene expression which escalate the AIP level indicating that the cell mass has reached a threshold density(Novick et al., 1995). On account of these autoinducing peptides (AIP's) Staphylococcus aureus strains has been categorized (Dufour et al., 2002) and every single AIP's stimulate the associated agr $\mathrm{C}$ protein striving with others to unite with the receptor (Lyon et al., 2002) for the genesis of infection in the host cell.

\section{Streptomycetes}

Streptomycetes, being the largest genus of Actinobacteria tends to live in the soil ecosystem. To transfer their message these group of spore forming gram positive bacteria (Anderson and Wellington, 2001) employ $\gamma$ butyrolactones as auto inducers and regulate the production of secondary metabolite through quorum sensing system. This bacterium is known to produce many useful antibiotics like neomycin, chloramphenicol etc (Akagawa et al., 1975; Distler et al., 1987; Dulmate, 1953). A great mystery lies in the cell communication of these bacteria owing to its chemical structure which is similar to the Acyl-homoserine lactones (AHL's) hence a lot of research work is required on this bacteria regarding cell to cell communication.

\section{Quorum quenching}

Unlike QS systems which is known to initiate communication between bacterial cells; quorum quenching is a phenomenon of interference in this communication with the help of various compounds (Turan and Engin, 2018). The technique of quorum quenching can be used in therapies against the microbial infestation, colonization, and infection (Czajkowski and Jafra, 2009; Dong et al., 2002; Uroz et al., 2003). The phenomenon of quorum quenching is seen in many groups of bacteria like Bacillus where signal transduction is inactivated by an enzyme (Dong et al., 2001) other than this A. tumefaction (Zhang et al., 2002), S. typhimurium, E. coli (Surette et al., 1999; Taga et al., 2001; Xavier and Bassler, 2003), $P$. aeroginosa (Mathesius et al., 2003) and $S$. aureus (Rothfork et al., 2004) also have quorum quenching mechanism.

It is evident that bacteria use a universal language known as auto inducers for communication with each other through a complex system of activities called quorum sensing. Mechanism of quorum sensing is different in gram negative and gram positive bacteria as signaling molecule AHL's and AIP's respectively are formed for their communication. Another thing that came into prominence through this article is every bacterium has a very specific quorum sensing mechanism which is distinct from other sets of bacteria to compete with other bacterial flora vital for its survival in the host environment.

\section{References}

Ahmer, B.M., van Reeuwijk, J., Timmers, C.D., Valentine, P.J., Heffron, F. 1998. Salmonella typhimurium encodes an SdiA homolog, a putative quorum sensor of the LuxR family, that 
regulates genes on the virulence plasmid. J. Bacteriol. 180, 1185-1193.

Akagawa, H., Okanishi, M., Umezawa, H. 1975. A plasmid involved in chloramphenicol production in Streptomyces venezuelae: evidence from genetic mapping. J. Gen. Microbiol. 90, 336-346.

Anderson, A.S., Wellington, E. 2001. The taxonomy of Streptomyces and related genera. Int. J. Syst. Evol. Microbiol. 51, 797-814.

Asad, S., Opal, S.M. 2008. Bench-to-bedside review: Quorum sensing and the role of cell-to-cell communication during invasive bacterial infection. Crit. Care $12,236$.

Czajkowski, R., Jafra, S. 2009. Quenching of acyl-homoserine lactone-dependent quorum sensing by enzymatic disruption of signal molecules. Acta Biochim. Pol. 56, 1-16.

Daoust, J. 1997. Salmonella species, in: Doyle, M P., Beuchat, LR., Montville, T. (Ed.), Food Microbiology: Fundamentals and Frontiers. Washington, DC, pp. 129-158.

De Kievit, T.R., Iglewski, B.H. 2000. Bacterial Quorum Sensing in Pathogenic Relationships. Infect. Immun. 68, 4839-4849.

Diggle, S.P., Williams, P. 2017. Quorum Sensing, in: Reference Module in Life Sciences. Elsevier.

Distler, J., Ebert, A., Mansouri, K., Pissowotzki, K., Stockmann, M., Piepersberg, W. 1987. Gene cluster for streptomycin biosynthesis in Streptomyces griseus: nucleotide sequence of three genes and analysis of transcriptional activity. Nucleic Acids Res. 15, 8041-8056.

Dong, Y.-H., Gusti, A.R., Zhang, Q., Xu, J.L., Zhang, L.-H., 2002. Identification of quorum-quenching $\mathrm{N}$-acyl homoserine lactonases from Bacillus species. Appl.
Environ. Microbiol. 68, 1754-1759.

Dong, Y.H., Wang, L.H., Xu, J.L., Zhang, H.B., Zhang, X.F., Zhang, L.H. 2001. Quenching quorum-sensing-dependent bacterial infection by an $\mathrm{N}$-acyl homoserine lactonase. Nature 411, 813817.

Dufour, P., Jarraud, S., Vandenesch, F., Greenland, T., Novick, R.P., Bes, M., Etienne, J., Lina, G. 2002. High Genetic Variability of the agr Locus in Staphylococcus Species. J. Bacteriol. 184, 1180-1186.

Dulmage, H.T. 1953. The production of neomycin by Streptomyces fradiae in synthetic media. Appl. Microbiol. 1, 103-106.

Gambello, M.J., Iglewski, B.H. 1991. Cloning and characterization of the Pseudomonas aeruginosa lasR gene, a transcriptional activator of elastase expression. J. Bacteriol. 173, 30003009.

Hogan, D.A. 2006. Talking to themselves: autoregulation and quorum sensing in fungi. Eukaryot. Cell 5, 613-619.

Hughes, D.T., Sperandio, V. 2008. Interkingdom signalling: communication between bacteria and their hosts. Nat. Rev. Microbiol. 6, 111-120.

Ibarra, J.A., Steele-Mortimer, O. 2009. Salmonella--the ultimate insider. Salmonella virulence factors that modulate intracellular survival. Cell. Microbiol. 11, 1579-1586.

Ji, G., Beavis, R.C., Novick, R.P. 1995. Cell density control of staphylococcal virulence mediated by an octapeptide pheromone. Proc. Natl. Acad. Sci. U. S. A. 92, 12055-12059.

Karmali, M.A., Steele, B.T., Petric, M., Lim, C. 1983. Sporadic cases of haemolyticuraemic syndrome associated with faecal cytotoxin and cytotoxinproducing Escherichia coli in stools. Lancet 1, 619-620. 
Knutton, S., Baldini, M.M., Kaper, J.B., McNeish, A.S. 1987. Role of plasmidencoded adherence factors in adhesion of enteropathogenic Escherichia coli to HEp-2 cells. Infect. Immun. 55, 78-85.

Lu, H.D., Pearson, E., Ristroph, K.D., Duncan, G.A., Ensign, L.M., Soo Suk, J., Hanes, J., Prud'homme, R.K. 2018. Pseudomonas aeruginosa Pyocyanin Production Reduced by QuorumSensing Inhibiting Nanocarriers. Int. J. Pharm.

Lyon, G.J., Novick, R.P. 2004. Peptide signaling in Staphylococcus aureus and other Gram-positive bacteria. Peptides 25, 1389-1403.

Lyon, G.J., Wright, J.S., Muir, T.W., Novick, R.P. 2002. Key determinants of receptor activation in the agr autoinducing peptides of Staphylococcus aureus. Biochemistry 41, 10095-10104.

Mathesius, U., Mulders, S., Gao, M., Teplitski, M., Caetano-Anolles, G., Rolfe, B.G., Bauer, W.D. 2003. Extensive and specific responses of a eukaryote to bacterial quorum-sensing signals. Proc. Natl. Acad. Sci. U. S. A. 100, 1444-1449.

Moon, H.W., Whipp, S.C., Argenzio, R.A., Levine, M.M., Giannella, R.A. 1983. Attaching and effacing activities of rabbit and human enteropathogenic Escherichia coli in pig and rabbit intestines. Infect. Immun. 41, 1340 1351.

Mota, L.J., Cornelis, G.R. 2005. The bacterial injection kit: type III secretion systems. Ann. Med. 37, 234-249.

Nealson, K.H., Platt, T., Hastings, J.W. 1970. Cellular control of the synthesis and activity of the bacterial luminescent system. J. Bacteriol. 104, 313-322.

Novick, R.P., Projan, S.J., Kornblum, J., Ross, H.F., Ji, G., Kreiswirth, B., Vandenesch, F., Moghazeh, S. 1995. The agr P2 operon: an autocatalytic sensory transduction system in Staphylococcus aureus. Mol. Gen. Genet. 248, 446-458.

Novick, R.P., Ross, H.F., Projan, S.J., Kornblum, J., Kreiswirth, B., Moghazeh, S. 1993. Synthesis of staphylococcal virulence factors is controlled by a regulatory RNA molecule. EMBO J. 12, 3967-3975.

Ochsner, U.A., Koch, A.K., Fiechter, A., Reiser, J. 1994. Isolation and characterization of a regulatory gene affecting rhamnolipid biosurfactant synthesis in Pseudomonas aeruginosa. J. Bacteriol. 176, 2044-2054.

Paharik, A.E., Parlet, C.P., Chung, N., Todd, D.A., Rodriguez, E.I., Van Dyke, M.J., Cech, N.B., Horswill, A.R. 2017. Coagulase-Negative Staphylococcal Strain Prevents Staphylococcus aureus Colonization and Skin Infection by Blocking Quorum Sensing. Cell Host Microbe 22, 746-756.

Papenfort, K., Bassler, B.L. 2016. Quorum sensing signal-response systems in Gram-negative bacteria. Nat. Rev. Microbiol. 14, 576-588.

Rothfork, J.M., Timmins, G.S., Harris, M.N., Chen, X., Lusis, A.J., Otto, M., Cheung, A.L., Gresham, H.D. 2004. Inactivation of a bacterial virulence pheromone by phagocyte-derived oxidants: new role for the NADPH oxidase in host defense. Proc. Natl. Acad. Sci. U. S. A. 101, 13867-13872.

Saenz, H.L., Augsburger, V., Vuong, C., Jack, R.W., Götz, F., Otto, M. 2000. Inducible expression and cellular location of AgrB, a protein involved in the maturation of the staphylococcal quorum-sensing pheromone. Arch. Microbiol. 174, 452-455.

Singh, P.K., Schaefer, A.L., Parsek, M.R., Moninger, T.O., Welsh, M.J., Greenberg, E.P. 2000. Quorum-sensing signals indicate that cystic fibrosis lungs 
are infected with bacterial biofilms. Nature 407, 762-764.

Smith, R.S., Iglewski, B.H. 2003. $P$. aeruginosa quorum-sensing systems and virulence. Curr. Opin. Microbiol. 6, $56-60$.

Sperandio, V., Torres, A.G., Jarvis, B., Nataro, J.P., Kaper, J.B. 2003. Bacteriahost communication: the language of hormones. Proc. Natl. Acad. Sci. U. S. A. $100,8951-8956$.

Stevens, A.M., Dolan, K.M., Greenberg, E.P. 1994. Synergistic binding of the Vibrio fischeri LuxR transcriptional activator domain and RNA polymerase to the lux promoter region. Proc. Natl. Acad. Sci. U. S. A. 91, 12619-12623.

Surette, M.G., Miller, M.B., Bassler, B.L., 1999. Quorum sensing in Escherichia coli, Salmonella typhimurium, and Vibrio harveyi: a new family of genes responsible for autoinducer production. Proc. Natl. Acad. Sci. U. S. A. 96, 1639-1644.

Taga, M.E., Semmelhack, J.L., Bassler, B.L., 2001. The LuxS-dependent autoinducer AI-2 controls the expression of an ABC transporter that functions in AI-2 uptake in Salmonella typhimurium. Mol. Microbiol. 42, 777-793.

Tannock, G.W., Ghazally, S., Walter, J., Loach, D., Brooks, H., Cook, G., Surette, M., Simmers, C., Bremer, P., Dal Bello, F., Hertel, C. 2005. Ecological behavior of Lactobacillus reuteri $100-23$ is affected by mutation of the luxS gene. Appl. Environ. Microbiol. 71, 8419-8425.

Tseng, B.S., Majerczyk, C.D., Passos da Silva, D., Chandler, J.R., Greenberg, E.P., Parsek, M.R. 2016. Quorum Sensing Influences Burkholderia thailandensis Biofilm Development and Matrix Production. J. Bacteriol. 198, 2643-2650.

Tu, X., Nisan, I., Yona, C., Hanski, E.,
Rosenshine, I. 2003. EspH, a new cytoskeleton-modulating effector of enterohaemorrhagic and entero pathogenic Escherichia coli. Mol. Microbiol. 47, 595-606.

Turan, N.B., Engin, G.Ö. 2018. Quorum Quenching, in: Comprehensive Analytical Chemistry.

Uroz, S., D’Angelo-Picard, C., Carlier, A., Elasri, M., Sicot, C., Petit, A., Oger, P., Faure, D., Dessaux, Y. 2003. Novel bacteria degrading $\mathrm{N}$-acylhomoserine lactones and their use as quenchers of quorum-sensing-regulated functions of plant-pathogenic bacteria. Microbiology 149, 1981-1989.

Vega, N.M., Allison, K.R., Samuels, A.N., Klempner, M.S., Collins, J.J., 2013. Salmonella typhimurium intercepts Escherichia coli signaling to enhance antibiotic tolerance. Proc. Natl. Acad. Sci. U. S. A. 110, 14420-14425.

Walker, T.S., Bais, H.P., Déziel, E., Schweizer, H.P., Rahme, L.G., Fall, R., Vivanco, J.M., 2004. Pseudomonas aeruginosa-plant root interactions. Pathogenicity, biofilm formation, and root exudation. Plant Physiol. 134, 320331.

Walters, M., Sperandio, V. 2006. Quorum sensing in Escherichia coli and Salmonella. Int. J. Med. Microbiol. 296, 125-131.

Wang, D., Ding, X., Rather, P.N. 2001. Indole can act as an extracellular signal in Escherichia coli. J. Bacteriol. 183, 4210-6. doi:10.1128/JB.183.14.42104216.2001

Wang, X.D., de Boer, P.A., Rothfield, L.I. 1991. A factor that positively regulates cell division by activating transcription of the major cluster of essential cell division genes of Escherichia coli. EMBO J. 10, 3363-3372.

Waters, C.M., Bassler, B.L. 2005. Quorum sensing: cell-to-cell communication in 
bacteria. Annu. Rev. Cell Dev. Biol. 21, 319-346.

Wong, A., Rodrigue, N., Kassen, R. 2012. Genomics of adaptation during experimental evolution of the opportunistic pathogen Pseudomonas aeruginosa. PLoS Genet. 8, e1002928.

Xavier, K.B., Bassler, B.L. 2003. LuxS quorum sensing: more than just a numbers game. Curr. Opin. Microbiol. 6, 191-197.

Yoon, S.S., Hennigan, R.F., Hilliard, G.M., Ochsner, U.A., Parvatiyar, K., Kamani, M.C., Allen, H.L., DeKievit, T.R., Gardner, P.R., Schwab, U., Rowe, J.J., Iglewski, B.H., McDermott, T.R.,
Mason, R.P., Wozniak, D.J., Hancock, R.E.W., Parsek, M.R., Noah, T.L., Boucher, R.C., Hassett, D.J. 2002. Pseudomonas aeruginosa anaerobic respiration in biofilms: relationships to cystic fibrosis pathogenesis. Dev. Cell 3, 593-603.

Zhang, R., Pappas, K.M., Pappas, T., Brace, J.L., Miller, P.C., Oulmassov, T., Molyneaux, J.M., Anderson, J.C., Bashkin, J.K., Winans, S.C., Joachimiak, A. 2002. Structure of a bacterial quorum-sensing transcription factor complexed with pheromone and DNA. Nature 417, 971-974.

\section{How to cite this article:}

Vandita Kohli, Saima Rehman, Srinu Rathlavath and Deepak Aggarwal. 2018. Quorum Sensing: Survival Strategy of Microbes. Int.J.Curr.Microbiol.App.Sci. 7(05): 165-172. doi: https://doi.org/10.20546/ijcmas.2018.705.021 